\title{
Forecasting the oil spill impacts on coastal desalination plants in United Arab Emirates
}

\author{
W. El-Sayed Elshorbagy ${ }^{1} \&$ A. Awad Elhakeem ${ }^{2}$ \\ ${ }^{1}$ Civil and Environmental Engineering Department, UAE University, \\ AlAin, United Arab Emirates \\ ${ }^{2}$ Water Resources Graduate Program, UAE University, \\ AlAin, United Arab Emirates
}

\begin{abstract}
Desalinated water is the major and only source of domestic demands in the United Arab Emirates (UAE) as well as in most Gulf Countries. Oil spill accidents in the Arabian Gulf have resulted in a shutdown of several coastal desalination plants in the UAE and eventually jeopardized the domestic water supply. Forecasting the impacts of such events is therefore a necessary requirement so that adequate precaution measures can be taken. Based on numerical modeling technique, the Arabian Gulf hydrodynamics, and oil-spill trajectory have been simulated using a 3-Dimensional calibrated hydrodynamic/ oil-spill model. A broad set of hypothetical oil slicks have been employed to assess the possible risks on five strategic coastal desalination plants along the United Arab Emirates coastline known to produce more than $90 \%$ of the desalinated water in the country. A set of points covering an approximate area of $130000 \mathrm{Km}^{2}$ between Strait of Hormuz to the East and the state of Qatar in the West and North to the Iranian coast have been identified as source points for the initiation of oil slicks. Oil slicks are assumed to be of $0.5 \mathrm{~m}^{3} / \mathrm{sec}$ discharge rate continuous for 1 day. For each of the targets identified, two spatial maps covering the study area have been produced indicating first, the critical dragging wind direction and second, the shortest traveling time of the oil slick towards the targeted locations. The produced special maps are thought to be of direct operational use to all five plants as it enables operators to estimate the risk associated with any oil slick occurring in the study area by estimating the travel time to the plant based on the location of the slick and the prevailing wind conditions at any time of the slick life.
\end{abstract}

Keywords: oil, spill, modeling, UAE, desalination, plants, Arabian Gulf. 


\section{Introduction}

Oil spilling is a chronicle phenomenon in the Arabian Gulf marine environment. Massive oil exploration along with the related loading and shipping activities of the produced oil has increased the risk of pollution throughout this shallow and high residence time (2-3 yrs.) water body. The characteristic lack of fresh water resources in the Arabian Gulf states has made desalination of sea water one of few available alternatives and the most economical and reliable one to secure the strategic needs and development plans. Therefore, it is an inevitable necessity to develop an early assessment of the risk associated with the oil spill impact on the major coastal desalination plants. Production expansion plans estimates that the United Arab Emirates is to produce well over 1000 MIGD by 2011 with an estimated investment of 30 billion USD over the next 5-10 years in power production and desalination industry [1].

\subsection{Gulf physical characteristics}

The Arabian Gulf has an area of $240000 \mathrm{Km}^{2}$ with an average depth of $25 \mathrm{~m}$ and total axis length of $1000 \mathrm{Km}$. The weather dominating phenomenon "Shamal" is seasonal northwesterly wind which occurs during winter and summer, its track is generally following the axis of the Gulf. The local winds are well recognized as the main driving force of oil on the sea surface. The mean effective wind speed varies between a minimum of $3.0 \mathrm{~m} \mathrm{~s}^{-1}$ in August and a maximum of $5.48 \mathrm{~m} \mathrm{~s}^{-1}$ in February [2]. Strong wind and rough sea conditions is more pronounced in winter than in summer. Statistics show that winter wind and sea surface conditions have been more favorable for the occurrence of oil spills. Residual currents are the main force responsible for the net transport of pollutants. Winddriven currents were found to be much larger than density-driven currents.

\section{Arabian Gulf Hydrodynamic Model}

MIKE3-HD has been selected for the current study. MIKE3-HD solves the timedependent classical conservation equations of mass and momentum in three dimensions, the so-called Reynolds-averaged Navier-Stokes equations, where the flow is decomposed into mean quantities and turbulent fluctuations. The flow field and pressure variation are computed in response to a variety of forcing functions, when provided with the bathymetry, bed resistance, wind field, hydrographic boundary conditions. The closure problem is solved in the turbulence module through the Boussinesq eddy viscosity concept relating the Reynolds stresses to the mean velocity field. To handle density variations, the equations for conservation of salinity and temperature are solved in the transport module. An equation of state constitutes the relation between the density and the variations in salinity and temperature. Thus, the turbulence and the transport modules are integrated components of the hydrodynamic module, and the suite of those three constitutes the HD module. 


\subsection{Model setup}

The total area of the Gulf has been included in the simulation with a rectilinear grid of $3 \mathrm{Km}$ spacing in the two directions. This relatively high modeling resolution is meant to enable the possibility of investigating along-coastline flow details. In the vertical direction a system of 5 layers $20 \mathrm{~m}$ thick. The initial salt and temperature field distribution is prepared as 3-D data files using the software digitizing tool. The boundary initial salt and temperature conditions at the Strait of Hormuz are provided as time series, all initial conditions data is adopted from the Mt-Mitchell cruise oceanographic contour results [3]. Tidal induced flow was forced with the principle semi-diurnal., M2 and S2, and diurnal K1 and O1, constituents. See Table 1. Constant northwesterly wind blowing along the Gulf axis with a friction coefficient of 0.0026 is used in the HD simulation.

Table 1: Harmonic tidal constituents.

\begin{tabular}{|c|c|c|c|c|}
\hline Tidal Constituent & M2 & S2 & K1 & O1 \\
\hline Phase (H.m) & 0.76 & 0.29 & 0.29 & 0.29 \\
\hline Amplitude $\left(\mathrm{g}^{\circ}\right)$ & 299 & 335 & 57 & 55 \\
\hline
\end{tabular}

\subsection{Model tuning and calibration}

\subsubsection{Simulated and measured water levels}

Computed water levels at Abu Dhabi and Dubai are compared to measured values from Elshorbagy et al. [4]. Abu Dhabi data represents the early summer season in April, while Dubai compares for the winter season in November (see fig. 1). Both comparisons show fair agreement between the measured data and the model resulting water height.

\subsubsection{Computed and measured residual currents}

For the comparison of currents see fig. 2, mooring M2 point from the MtMitchell located at Latitude 2622.36 and Longitude 5345.87 is used. The M2 point lies in the deep region of the Gulf along the Iranian coast. Data from the current meter at depth of 10 meters are selected for comparing with the model's $20 \mathrm{~m}$ deep top layer averaged current. The $\mathrm{U}$ and $\mathrm{V}$ components where compared for the same period of time. Component $U$ in the model showed fair agreement to the measured data, while the V component showed less agreement. 

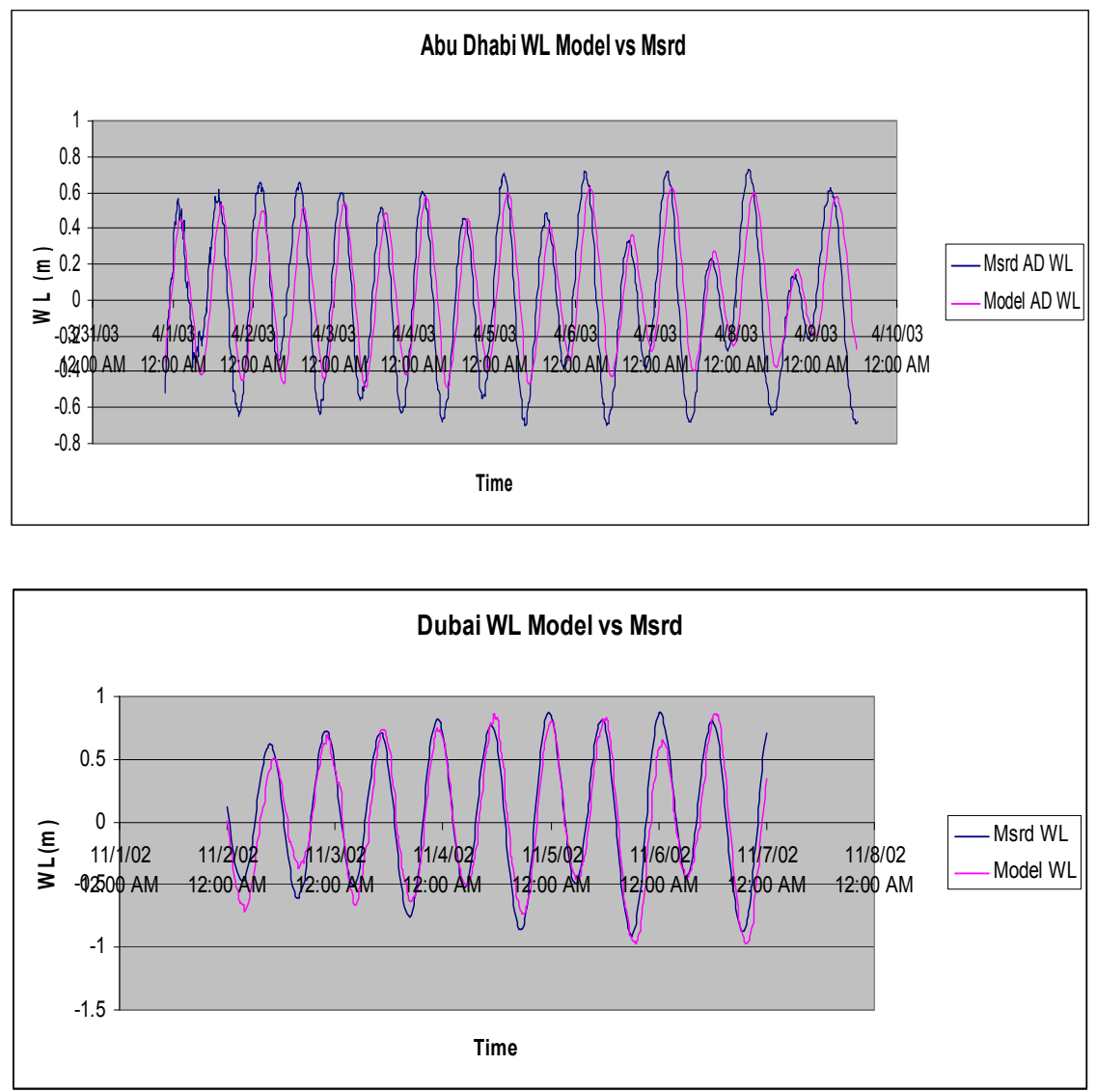

Figure 1: $\quad$ Measured and modeled water level in Abu Dhabi and Dubai.

\subsubsection{Arabian Gulf residual flow pattern}

The model-predicted average surface flow pattern agrees with the flow pattern features reported in previous studies $[3,5]$. In the southern part, the counter clockwise gyre up to Qatar peninsula is seen. Also in the northern half the south westerly jet flow along the Saudi and Iranian coasts is seen while the central and upper portion of the north half of the Gulf is dominated by relatively calm waters with currents hardly exceeding $10 \mathrm{~cm} / \mathrm{s}$ (see fig. 3 ). 

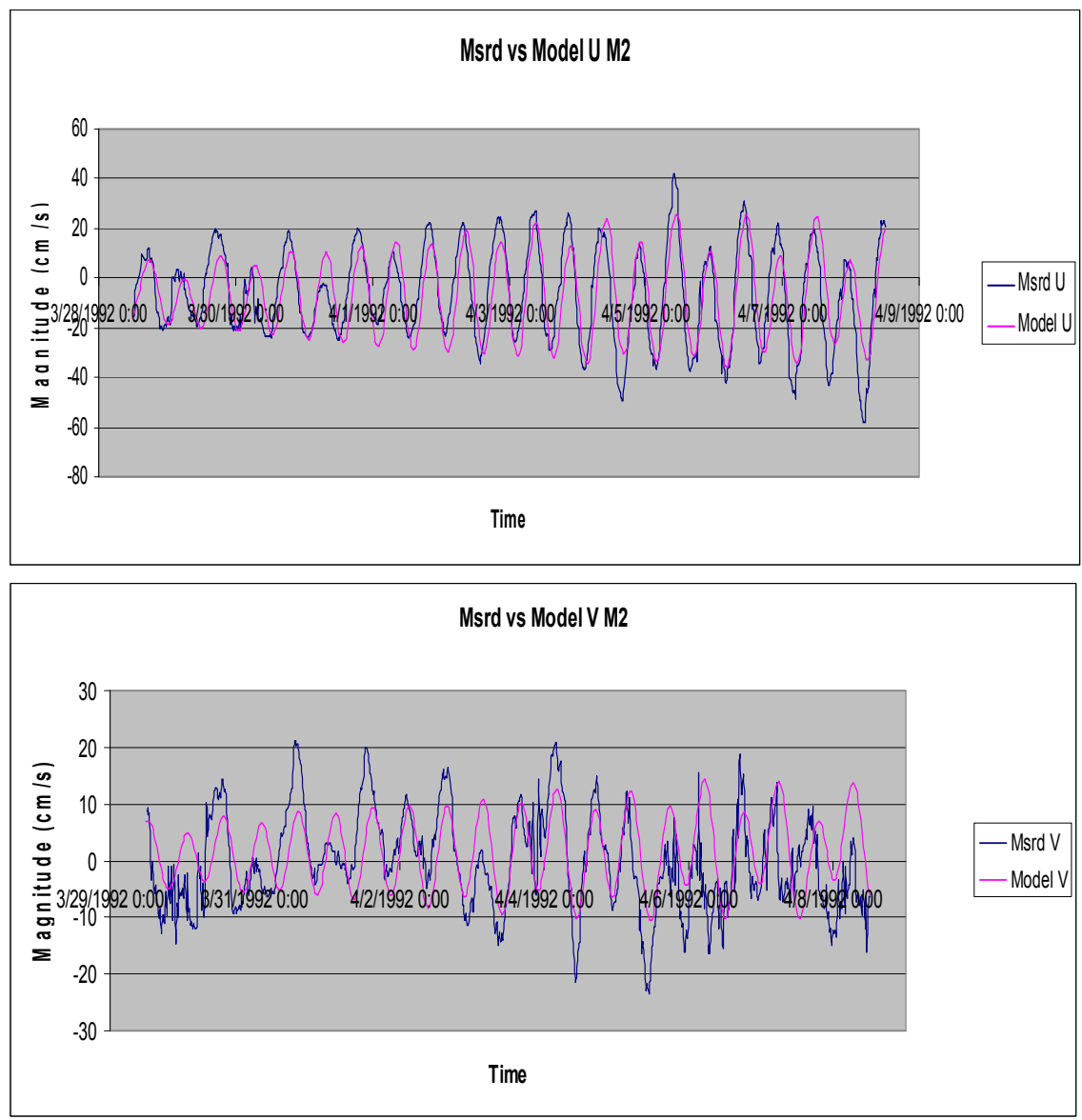

Figure 2: $\quad$ Measured and modeled current components $\mathrm{U}$ and V.

\section{Oil spill model}

\subsection{Spill analysis model setup}

MIKE3-SA module solves the so-called Fokker-Planck equation for suspended oil substances in two dimensions through the introduction of consistent random walk particle method. The wind driven currents are the dominating force in the oil spill movement in the gulf. It is well known that the oil moves on the sea surface due to the combined action of wind generated currents, wind induced waves, and by direct wind shear. This fact is well documented in previous published articles in the Arabian Gulf. The sensitivity study shows that the density currents in the region adjacent to the UAE coast are of potential importance for oil slick movement. Information found on wind parameters during literature search conducted earlier that is usually incomplete. The 


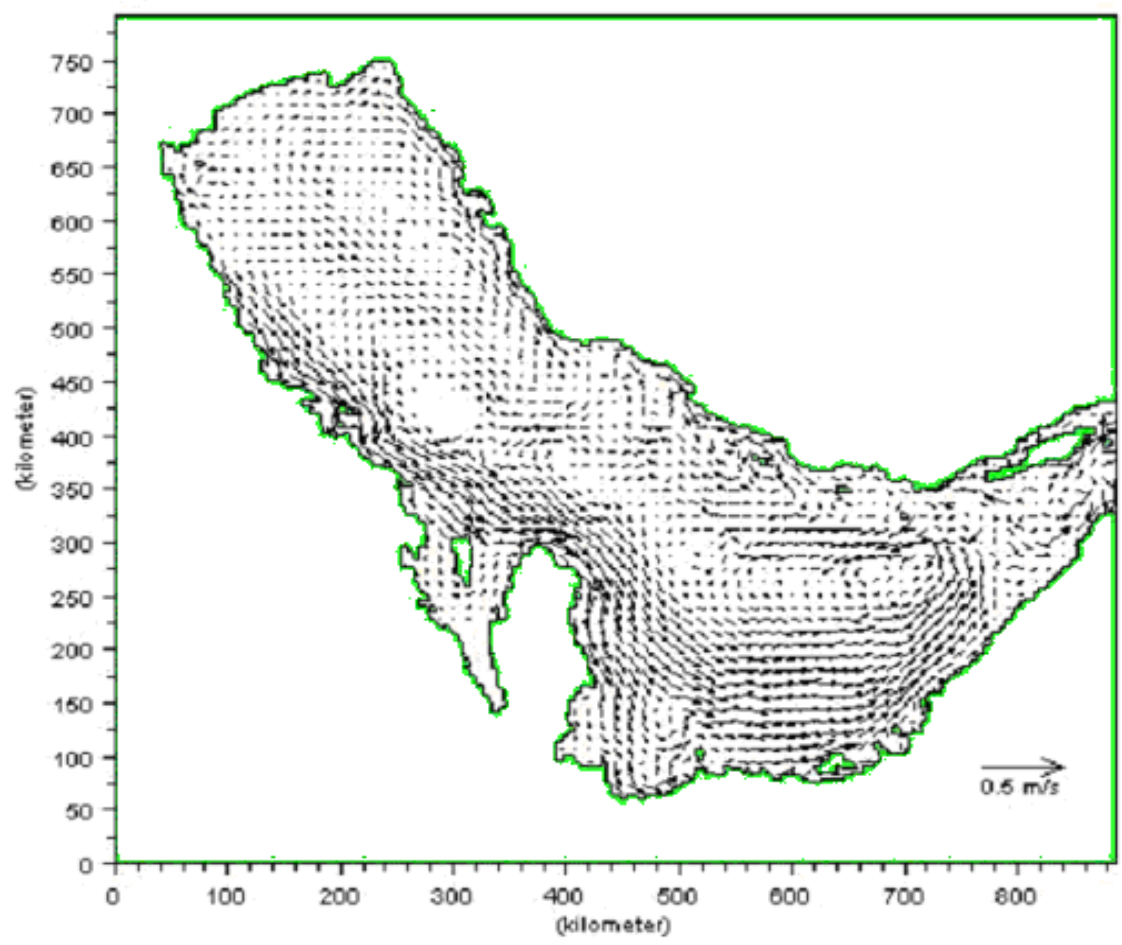

Figure 3: $\quad$ Simulated one-month average residual surface flow.

sensitivity analysis indicates that accurate wind data is essential for accurate trajectory prediction. The wind parameters include comprehensive wind data in terms of magnitude and direction in space and time during the simulation period, wind drift coefficient either constant or variable, and wind drift angle. For the validation of the spill analysis model setup a range of data that was published on the Arabian Gulf region was used and results comparison with the produced trajectory to the well documented trajectory of AL-AHMADI oil spillage occasion in 1991.

The values used to setup the model where justified either adopted from the previous studies held in the region or otherwise an approximation based on the sensitivity study has been used.

\subsection{Spill analysis model testing and validation}

The combined hydrodynamics and spill analysis model simulation results was evaluated against the actual sightings and simulation on AL-AHMADI oil spill study conducted by the Water Resources and Environmental Division in King Fahad Univ. of Petroleum and Minerals "KFUPM". The incident that occurred over the period of January-May 1991 in the state of Kuwait in the upper part of 
the Arabian Gulf was documented in a published paper by Al-Rabeh et al. [2]. Available information in the paper was used as input to MIKE3-SA spill analysis model. The oil spill simulation results were then compared to the documented original spill.

The simulation results using the stated average monthly values of wind the angle and magnitude by Al-Rabeh showed that MIKE3-SA was in fair agreement to the sighting dates and track of both, the actual and predicted findings in the first three stations of Khafji, Safaniya, and Ras Al-Gar until the end of the first week of February. Deviation from the KFUPM predicted sighting dates starts to increase with time after that date. This was expected, as stated earlier, based on the limitation of using the average effective monthly wind data by MIKE3 instead of the daily average used for prediction in the KFUPM model. Yet, the predominant average effective monthly wind data produced a fair prediction during the first 19 days of the spill period. The deviation was amplified due to the effect of the less frequent reversed southeastern wind front documented in the MEPA report by Tawfiq and Olsen [6] which occurred after February 7, 1991 and acted to retard the propagation of the spill further southeast. The absence of this occasional reversed wind data caused MIKE3-SA to carry over the simulation with the average effective monthly wind data and drive the spill further southeast while the spill was held back with the reversed wind forcing. In general the predicted MIKE3-SA trajectory resembles the prediction of the KFUPM model track which does not come into interference with Abu-Ali island but else is drifted to the east and the retardation of the trajectory is only due to the reversed wind direction, while the actual trajectory retardation was partially due to the fact that the spill was held northeast of Abu-Ali [7] for a long time before it started circling around the island and again moving southwest. The KFUPM article also states that the oil comes to contact with the shoreline from latitude $2844^{\prime}$ 'to 27 , this is not found in the simulation results (fig. 4).

\section{Desalinated plants and source zoning}

\subsection{Desalination plants selection}

Intakes of a selected number of strategic desalination plants along the UAE coast mainly in Abu-Dhabi, Dubai, and Sharjah are considered as coastal points of interest in the spill impact analysis. Selection of points was based on their production capacity and their geographical location in an effort to evaluate the risk on the widest range of the UAE coast. The coordinates of the point are considered as observation points and time series is produced in the post processing stage to determine the arrival of oil to these specified locations.

\subsection{Zoning}

A zoning pattern has been produced for the area of the Arabian Gulf adjacent to the UAE. A system of 12 boxes of $75 \mathrm{~km}^{2}$ each constitutes the potential oil source release zones. The adopted distribution was determined based on two 

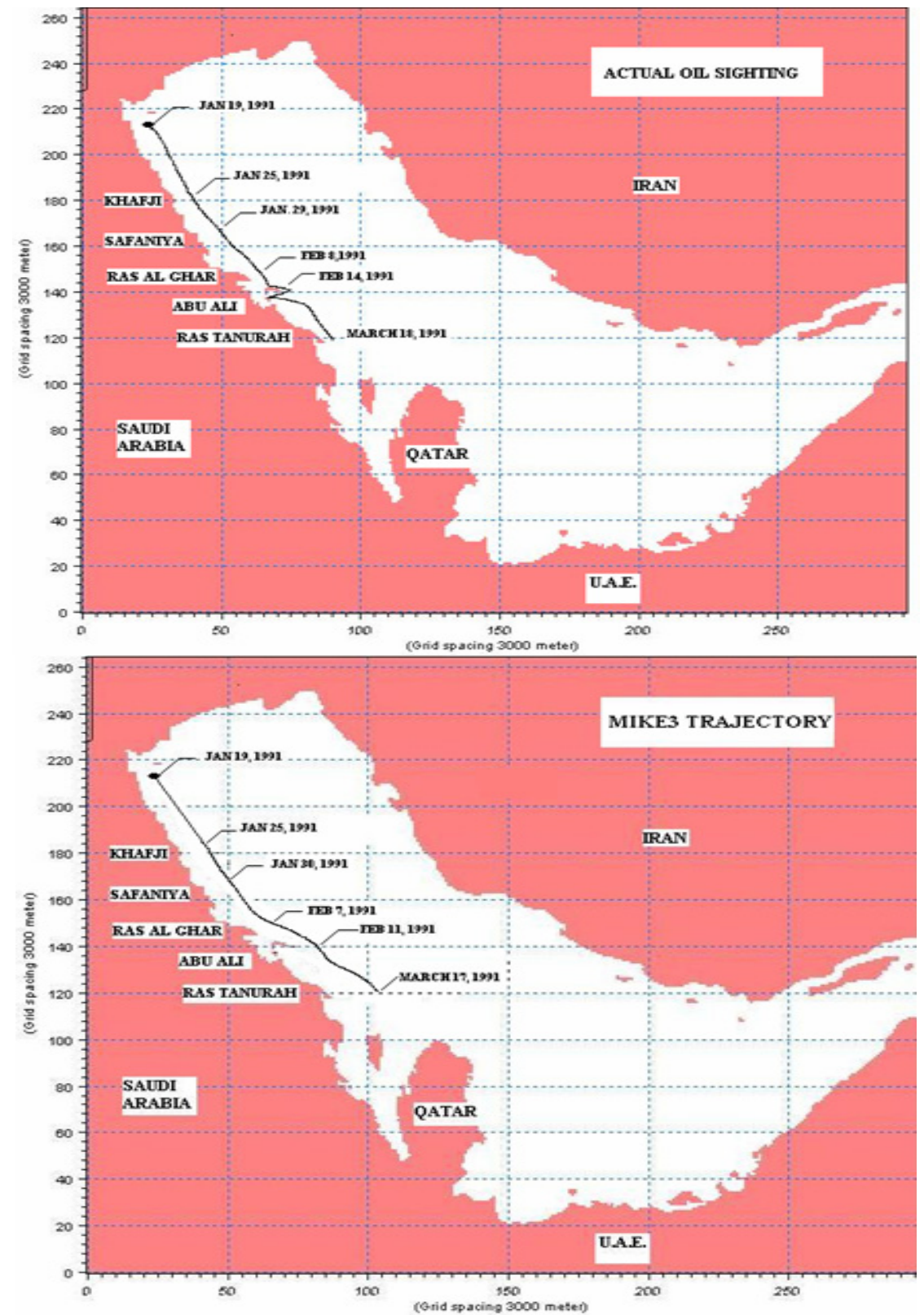

Figure 4: $\quad$ Simulated and actual Al-AHMADI spill trajectory.

constraints, first, is the actual location distribution of the oil loading terminals in the area, and second, the navigation routes followed by the oil tankers (see fig. 5). 


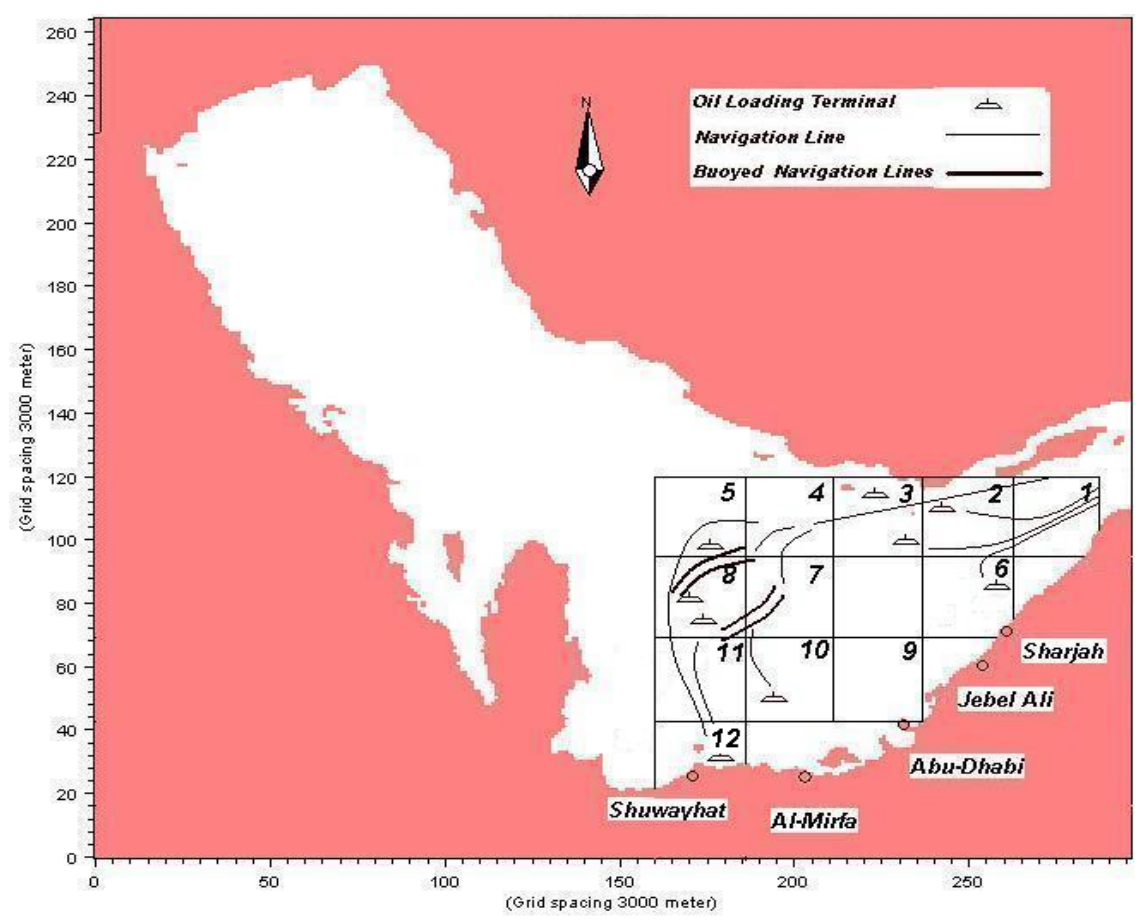

Figure 5: Plants locations, zoning, oil terminals and navigation lines.

The use of these two determinants covers the whole journey of oil tankers in and out of the Gulf and also during loading and unloading of oil so that most potential locations of oil spill occurrence are enclosed zones. The routs information used is recovered from the Admiralty Navigation Chart no. 2889 for the Arabian Gulf region.

\section{Results and risk assessment maps}

\subsection{Spill trajectories}

Spatial maps of the shortest slick arrival time and the associated critical wind direction are determined for each plant. Considering the worst extreme cases and observing the historical records of wind conditions in the gulf, constant wind with magnitude of $7 \mathrm{~m} / \mathrm{s}$ is applied in the simulation. In this approach, the exact angle between the source and the destination was measured and the Coriolis effect is considered to specify the wind direction in order to direct the slick hitting the destination exactly. However, the calculated angle is modified using trial and error approach to account for the trajectory deflection taking place once the slick enters the shallow areas close to the shore. Upon inspection of the early 
versions of contour maps, it was decided to introduce 3 supplementary zones (13-15) in several maps in order to refine the coarse resolution of travel time and wind direction observed in some areas. A 30 day simulation period using winter conditions is conducted in all considered scenarios from Jan. 19 to Feb. 18. The results of a total number of 64 simulations are analyzed and tabulated and contour maps are produced for travel time and associated wind directions for each desalination plant. Sample of the contour maps for Jebel-Ali desalination plant is presented here.

\subsection{Jebel-Ali desalination plant}

Approximately $100 \mathrm{~km}$ Northeast of AbuDhabi, Jebel-Ali desalination plant is located with about 180 MGD desalinating capacity, being the only desalination plant serving Dubai Emirate. Travel time contours range from 80 to $360 \mathrm{hrs}$ over the modeled area. Large travel times (greater than $300 \mathrm{hrs)}$ ) are occurring from the northern western corner in association with northwestern wind $\left(270^{\circ}\right)$. Travel times associated with spills originated from the northwestern to northern areas straight above the plant are brought about by the northwestern winds $\left(240-315^{\circ}\right)$ (see figures 6 and 7).

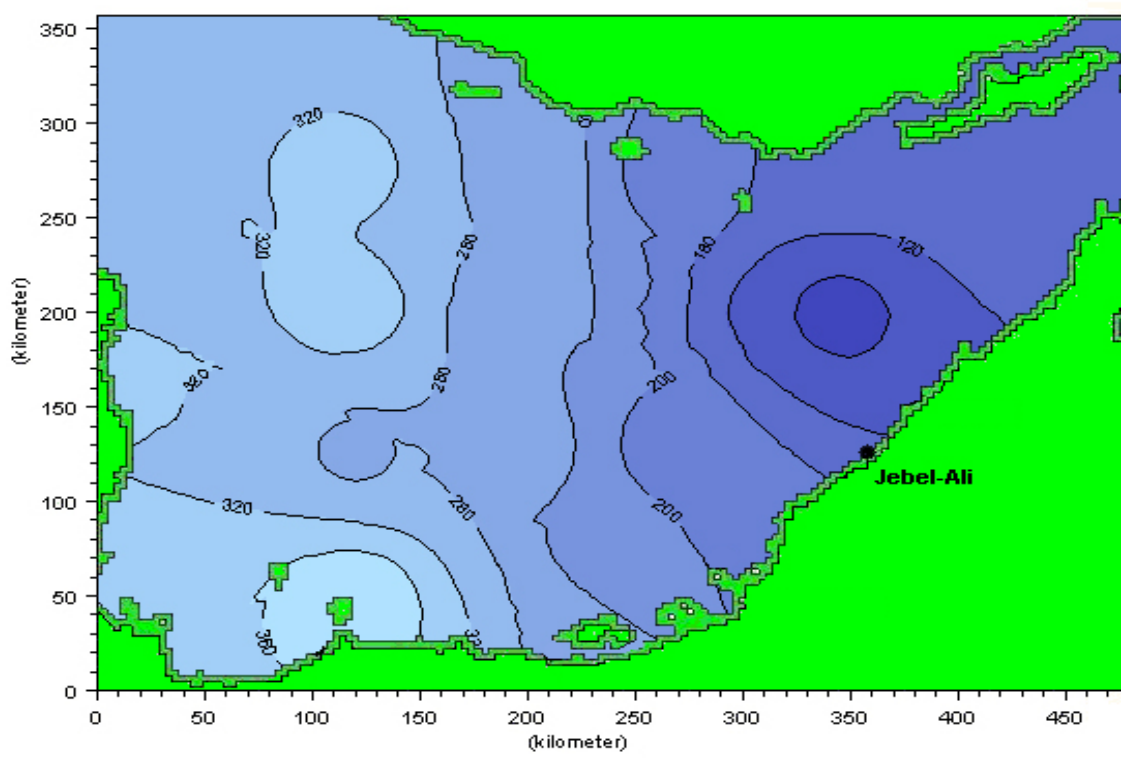

Figure 6: Shortest arrival times (hours) to Jebel-Ali desalination plant. 


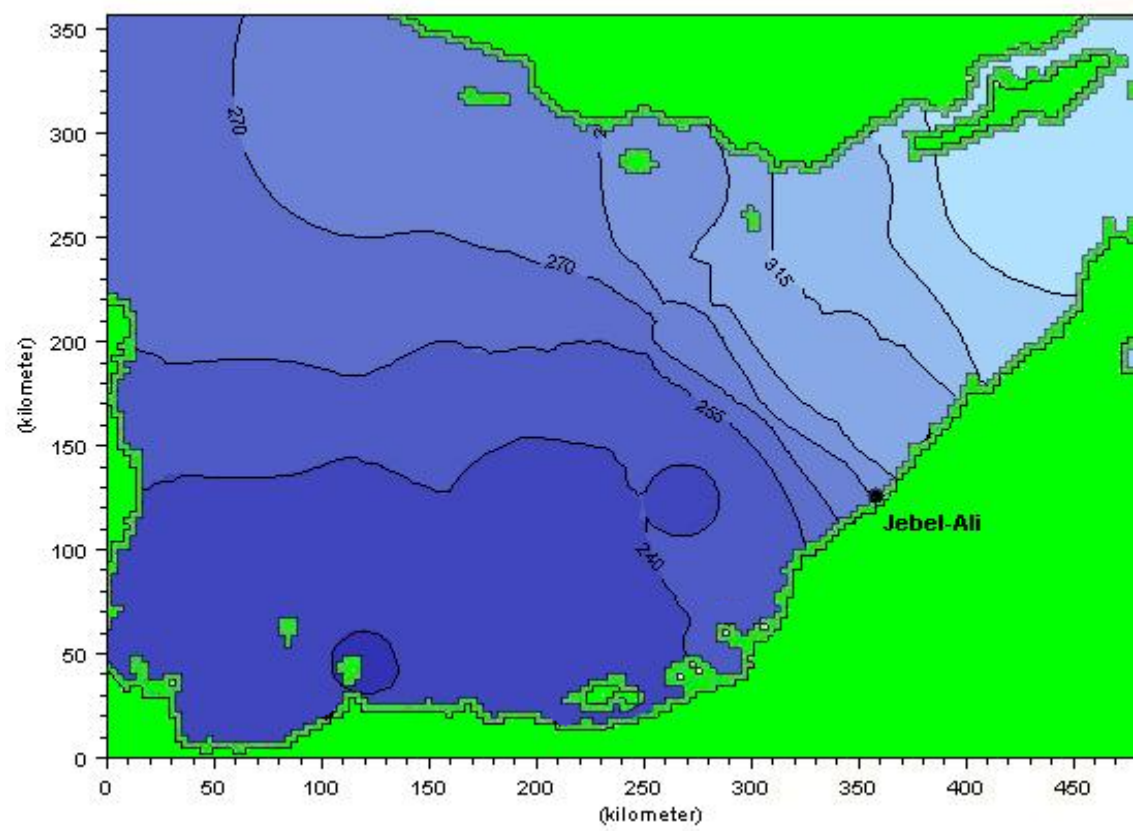

Figure 7: Critical wind direction associated with shortest arrival times.

\section{Summary and recommendations}

Hazard contour maps for the prediction of oil spill travel time and critical wind direction in association with five selected mega desalination plants along the UAE coast. Al-Shuwayhat, Al-Mirfa, Umm AlNar and Taweelah, Jebel-Ali and Al-Layah were selected as the most vital plants and their locations where set as observation points. To achieve such a task, three stages were carefully designed to form the operational frame work of the study; the hydrodynamic simulation, the oil spill simulation, and the impact assessment in terms of the contour maps processing and production.

The produced maps are of practical and direct benefit for the operators of the desalination plants and the water authorities in UAE. The source/destination travel time of an oil slick at any time is directly spotted and the associated critical wind direction is pointed out by locating the spill on the contour maps. Such identification will enable plant operators to prepare for combating oil spill incidents. The current study could be further expanded to other potential coastal resources. Also the application of summer prevailing water and environmental conditions and other simulation periods would be important to address. Finally other models reflecting the effect of weathering processes on the migrating slick can be further investigated and be linked to different oil types as well. 


\section{References}

[1] www.trade.uktradeinvest.gov.uk/water/abu dhabi/

[2] Al-Rabeh A. H., Cekirge, H. M., and Gunay, N. Modeling the fate and transport of Al-Ahmadi oil spill. Water and Air Pollution 65, 257-279. 1992.

[3] Reynolds, R. M. Physical oceanography of the Gulf, Strait of Hormuz, and Gulf of Oman - results from the Mt Mitchell expedition. Marine Pollution Bulletin, 27, 35-59. 1993.

[4] Elshorbagy, W., Mir, H. A., and Taguchi, K. Hydrodynamic characterization and modeling of the Arabian Gulf. Submitted to ASCE, Journal of Waterway, Port, Coastal, and Oceanic Engineering. 2004a.

[5] Elshorbagy, W., Mir, H. A., Ichikawa, T., and Terasawa, T. A three dimensional model application to study the residual flow in the Arabian Gulf. Submitted to ASCE, Journal of Waterway, Port, Coastal, and Oceanic Engineering. 2004b.

[6] Tawfiq and Olsen, D. A. Saudi Arabia's response to the 1991 Gulf oil spill. Marine Pollution Bulletin, 27, 333-345. 1993.

[7] Spaulding, M. L., Anderson, E. L., Isaji, T. and Howlett, E. Simulation of the oil trajectory and fate in the Arabian Gulf from the Mina Al Ahmadi spill. Marine Environmental Research, 36, 79-115. 1993. 